\title{
Hide a Dagger Behind a Smile: A Review of How Collectivistic Cultures Compete More Than Individualistic Cultures a
}

\author{
Kaidi Wu, Thomas Talhelm
}

https://doi.org/10.1093/oxfordhb/9780190060800.013.26 Pages C26P1-C26N1

Published: 20 April 2023

\begin{abstract}
In this chapter, we review cultural differences in people's attitudes about competition, why cultures differ in competition, and how they compete in different ways. Researchers have long associated collectivistic culture with harmony and cooperation. However, the bulk of the evidence suggests that collectivistic cultures compete more, and more intensely, than individualistic cultures. Collectivists are more likely to see competition as zero-sum, engage in social comparison, and base their self-worth on common standards rather than self-defined goals. This raises a paradox: where does the popular conception of harmony in collectivism come from? In reviewing prior studies, we find that people in collectivistic cultures tend to use indirect, hidden methods to compete against others. This allows for an outward harmony, without negating competition. We ask whether competition in collectivistic cultures is only stronger when competing with outsiders. Studies reject this speculation. Rather, people in collectivistic cultures compete more with in-group members and are more vigilant toward classmates and co-workers. Next, we explore how people from different cultures decide to enter into competition. We find that collectivists' tendency to enter into prestigious competitive environments might end up harming them. Finally, we discuss whether there can be versions of collectivistic groups without competition or whether this is a utopian dream.
\end{abstract}

Keywords: culture, collectivism, competition, sabotage, social comparison, zero-sum belief

Subject: Social Psychology, Psychology

Series: Oxford Library of Psychology

Collection: Oxford Handbooks Online

Hide a dagger behind a smile.

On April 1, 2013, Yang Huang, a medical student from prestigious Fudan University in Shanghai, drank from a water dispenser in his dormitory and fell violently ill. Two weeks later, Huang died of poisoning. The culprit was none other than his roommate, a fellow medical student who held a held a grudge against him and laced the water with thallium (Zhuang, 2013). Within the same year, Zijie Wang, a 26-year-old graduate student at Queen's University was caught on camera dosing his co-worker with a carcinogenic chemical NDMA (Faris, 2018).

These were far from isolated incidents amid the competitive landscape of higher education in China. Students have committed similar crimes against their fellow classmates at Tsinghua University, Peking University, and the China University of Mining and Technology (Pan, 2013). Overseas, a 22-year-old 
Chinese student at Lehigh University admitted to sickening his roommate by sprinkling thallium over his food over an extended period of time (Swenson, 2018).

The tacit ill will directed at close others stands in stark contrast to the cultural ideals of collectivism.

Cultural psychology has long been highlighting the idea that people in East Asia attune to a collective self, placing high values on interdependence and social harmony. In contrast, Westerners tend to focus on an individual self, emphasizing independence and personal agency (Markus \& Kitayama, 1991, 2010; Triandis et al., 1988). Much literature on competition and cooperation tends to associate collectivism with cooperation and individualism with competition (Bonta, 1997; C. C. Chen et al., 1998).

However, accumulating empirical evidence has suggested otherwise. Compared to people in individualistic cultures, people in collectivistic cultures place just as much importance on the role of competition (Watkins, 2006), are more likely to subscribe to zero-sum beliefs (Różycka-Tran et al., 2015), and are more suspicious of in-group members (S. S. Liu et al., 2019). For example, one study asked people in the United States and China to anticipate what aspiring actors would do when they were trying out for a leading role. People in China were more likely to anticipate that other people would compete unethically, such as by "poisoning other actresses' food."

Why is there so much competition in seemingly harmonious societies? We could find no comprehensive review on this question, except for one overview on the topic of culture and competition, focusing on China (H. Leung \& Au, 2010). In this chapter, we connect different veins of research on cultural differences in competition. We first review cultural variation in people's attitudes about competition. Next, we discuss why and how people from different cultures compete. We argue that, in cultures that demand social harmony, people use tacit strategies to compete against others. This social vigilance is a consequence of collectivism, ${ }^{1}$ rather than the exception. Next, we explore how people from different cultures enter competitions and how it affects them afterwards. We end with a discussion of whether there can be versions of collectivistic societies without competition or whether this is a utopian dream.

\section{Views of Competition Across Cultures}

There is broad consensus about what competition means for different cultures. People in East Asia and the West alike associate competition with the goal of outperforming others, and they view cooperation as working with others to achieve collective goals (Keller \& Loewenstein, 2011). People across Europe, North America, and East Asia also generally agree about where competition often takes place, such as in the world economy, personal finance, work, education, politics, sports, science, military, fashion, beauty, and entertainment (Fülöp, 1999, 2000). However, there are distinct ways in which cultures differ in what they think about that competition.

Fülöp (2005) argues that there are systematic differences between stable, wealthy Western countries and developing, post-socialist countries like Hungary. Fülöp asked people to describe their thoughts on competition in open-ended responses, contrasting (1) countries with stable democracies and capitalist economies, such as the United States, Canada, and the United Kingdom, and (2) countries with emerging economies and less democratic governments. In more democratic nations, people tended to acknowledge that they live in competitive societies but felt neutral about the role of competition in society. They tended to describe competition with non-emotional words, focusing on its mechanistic aspects, with little detail of its negative consequences (Fülöp, 2000). This is similar to studies finding that French adolescents hold meritocratic beliefs about competition -it stimulates hard work and brings success (Fülöp et al., 2004).

This contrasts with respondents from Hungary, a country transitioning from a socialist society to a free enterprise economy. Participants from Hungary tended to think competition was negative. They associated it with cheating, bribery, jealousy, aggression, and survival (Fülöp \& Sándor, 2006; Watkins, 2010).

Similarly, people from post-communist countries such as Armenia, Georgia, and Ukraine described a more pessimistic, social-Darwinist view of competition (Fülöp et al., 2004; Roberts et al., 2000).

Much like their North American and Western European counterparts, people in Japan and Hong Kong view competition as an important driving force for individual improvement and societal advancement (Watkins, 2006). However, people in East Asia report enjoying competition less than North Americans (Houston et al., 2005). This research suggests it is important to separate people's views on competition's role in society from whether they like competition. 
There are also differences in whether people see competition and cooperation as opposites. One study found that North Americans view competition and cooperation as opposing processes, whereas people in East Asia see competition co-existing with cooperation (Keller \& Loewenstein, 2011). Researchers presented different work situations to participants in China and the United States and asked them whether each situation was cooperative or not. Some scenarios involved work groups with little competition, such as "Members don't try to perform better or faster than other members." In those cases, Americans assumed that situation was cooperative. The lack of competition meant cooperation. In contrast, people in China did not think that scenario implied cooperation. In other words, Americans assumed "low competition" means "cooperative," whereas participants in China did not.

This fits with other findings of how people interpret the intentions of people being helpful. Participants in America viewed going out of one's way to help others with their work as a signal of cooperation (Keller \& Loewenstein, 2011). People in China considered it to be uncooperative. To explain this counterintuitive finding, Keller and Loewenstein (2011) suggested that people in China would sense ulterior motives if a coworker is overeager to help; they would see unsolicited help as a way of gaining trust and information from them-information they would otherwise not be willing to share. In another study, people in China were far more likely than Americans to perceive overt friendliness and help as sabotage in disguise (S. S. Liu et al., 2019).

\section{Some Research Has Defined Competitiveness as a Part of Individualism}

Studies in cultural psychology have explicitly defined competition as a part of individualism and cooperativeness as a central feature of collectivism (Grimm et al., 1999; Singelis et al., 1995; Triandis \& Gelfand, 1998). For example, the Horizontal-Vertical Collectivism scale gives people more points on individualism if they agree with items like "winning is everything" and "it is important that I do my job better than others." In contrast, it gives people points for collectivism if they agree with cooperation: "I feel good when I cooperate with others" (Triandis \& Gelfand, 1998).

A meta-analysis of individual-collectivism scales found four different scales that included competition as a part of individualism (Oyserman et al., 2002). A more recent review similarly found individualism scales that measured competitiveness rather than independence per se (Vignoles et al., 2016). This assumption is evident in people's reactions to data that find the opposite. For example, when researchers found evidence that collectivistic cultures score higher competition, they called it "the most surprising result" (RóżyckaTran et al., 2015). This reaction is understandable given the prior theorizing on competition. In short, research on competition tends to associate competitive behavior with individualism and cooperative behavior with collectivism (C. C. Chen et al., 1998; Domino, 1992).

\section{Studies Find Collectivistic Cultures More Competitive Than Individualistic Cultures}

Despite this theorizing, evidence for the association between individualism and competition is mostly in the opposite direction. Most studies have found either no difference or that collectivistic cultures compete more. On self-reported measures of competitiveness, American college students scored no higher than students in China; nor did they score any lower on cooperativeness (Tang, 1999). Among fourth- through sixth-graders, European Americans (who tend to score higher on individualism) were no more competitive at social motive games than Mexican Americans (who tend to score higher on collectivism) (Knight et al., 1981).

More definitive data comes from a large research project that compared 12,000 students in 41 countries across the globe (Furnham et al., 1994). Researchers found that Asian countries (e.g., China, Japan, Korea, Singapore, India) actually score the highest on self-reported competitiveness. Data from the Programme for International Student Assessment (PISA) showed that students from Asian countries (e.g., Hong Kong, Korea, Singapore) report the highest level of competitiveness, whereas those from northern and central European countries (e.g., Denmark, Iceland, Austria) report the highest level of cooperativeness. Students in Asia were more likely to rate their school environment as competitive, agreeing with the statement that 
"Students are competing with each other." Students in Europe were more likely to agree with the statement,

"It seems that students are co-operating with others" (OECD, 2018). Similarly, in a study of zero-sum beliefs in 37 countries, people from collectivistic cultures reported a stronger belief that the world is zerosum than people in individualistic cultures (Różycka-Tran et al., 2015).

Studies that measure competitiveness through social games align with these findings. In one study, researchers had second-, fourth-, and sixth- graders in Belgium, Greece, the United States (including European Americans and Mexican Americans), and Japan play the Maximizing Difference Game (Toda et al., 1978). In this game, two players played 100 trials. During each trial, both players could choose either option A or B. If both players chose A, they each win six points. This outcome maximizes joint gain and personal gain. But if one player chooses B, they get five points and stick their partner with zero points. This outcome maximizes relative gain. The instructions did not give the children any explicit goals during the game. They were simply told to play a game in which they could win points.

The researchers measured competitiveness by the number of $B$ choices - the number of times a participant chose relative gain over the possibility of joint and personal gain. They found that children in Japan made more competitive choices than children from any other culture (Table 26.1).

Table 26.1 Maximizing difference game matrix. Within each cell, Player I gains the number of points on the left; Player II gains the number of points on the right.

\begin{tabular}{|c|c|c|c|}
\hline \multirow[t]{2}{*}{ Maximizing Difference Game } & & \multicolumn{2}{|c|}{ Player I } \\
\hline & & $A$ & B \\
\hline \multirow[t]{2}{*}{ Player II } & A & 6,6 & 0,5 \\
\hline & B & 5,0 & 0,0 \\
\hline
\end{tabular}

Another study had three- to five-year-old children in Taiwan and United States play a modified MarblePull Game (Sparkes, 1991; Figure 26.1). In the game, two children sit on opposite sides of a game board. At each end of the board, there is a hole the size of a disc. At the center of the board are two half-blocks held together by magnets. At the center of the half-blocks is a hollow space containing a disc. If both children choose to pull their half-block towards themselves, the block pulls apart and the disc stays at the center of the game board. This is a competitive choice. However, if one child pulls the disc and the other child lets him do so, then the disc is carried to that side and falls into the hole. This is a cooperative choice. The game ends when the children have cooperated 10 times and a total of 10 discs have fallen into one hole or the other. The study found that children in Taiwan spent more time pulling against each other rather than taking turns to win the game together. These findings suggest that people from collectivistic cultures are more competitive, and that this competitive assumption may paradoxically lead people from collectivistic cultures to achieve fewer joint gains. 


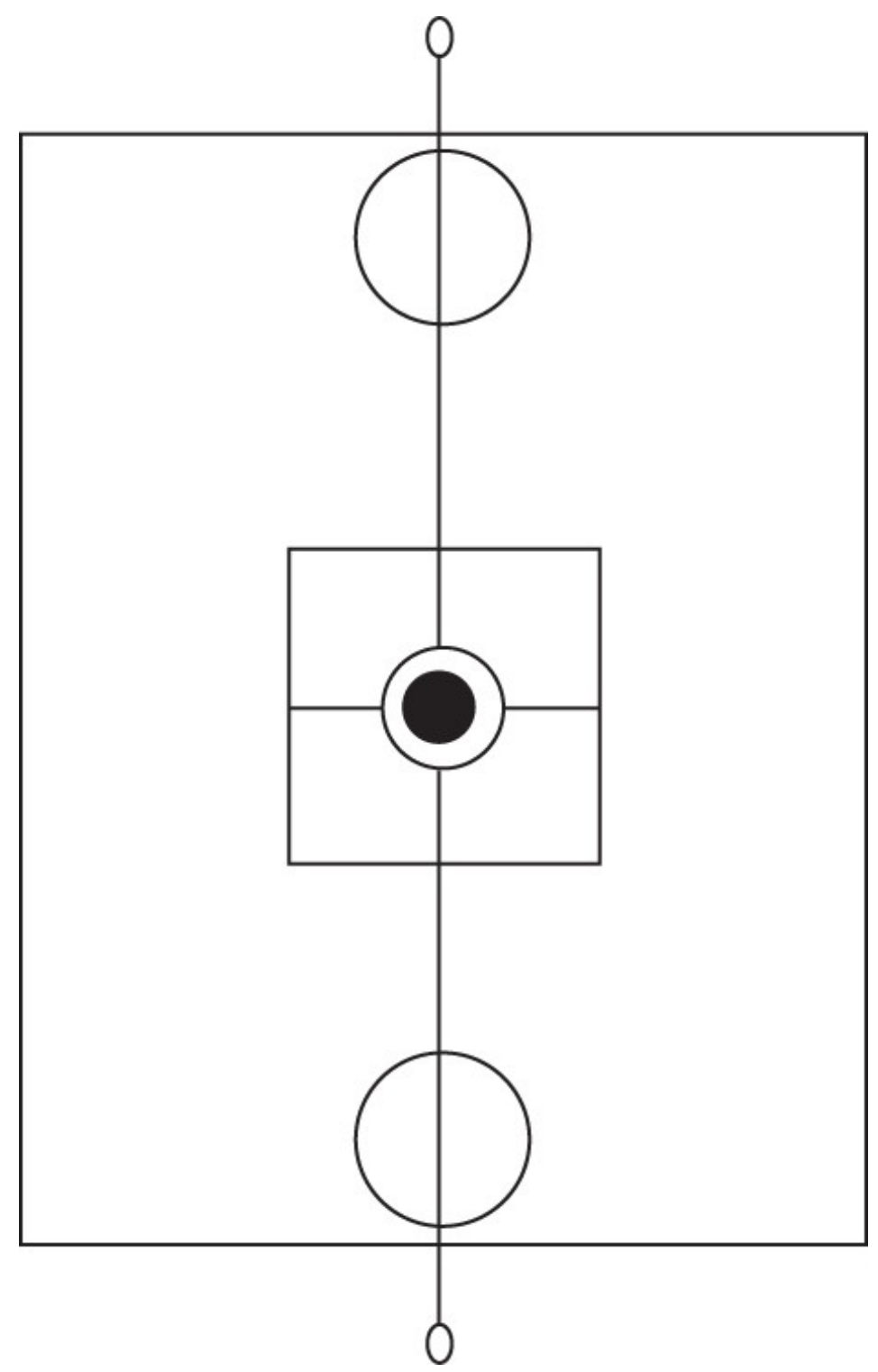

Gameboard for the modified marble-pull game.

Still, why do some studies find that collectivists cooperate to a greater extent than individualists (Domino, 1992)? Several studies point to the importance of monitoring and reputation. Some researchers have suggested that people in collectivistic cultures are not inherently more cooperative; they do so when there is a sanctioning system in place ( $\mathrm{H}$. Leung \& $\mathrm{Au}, 2010$ ). They default to acting in the interest of the group when doing otherwise would incur reputational cost (Yamagishi et al., 2008).

For example, (Yamagishi, 1988, 2003) put participants from America and Japan into groups to play a public goods game. Participants were given 50 cents and asked how much of the 50 cents they would give to other members of the group. The contributions would then be doubled and distributed equally among everyone. There was no public sanctioning in the game, which meant no group member would be punished if they contributed less than others. Participants in Japan showed lower social trust and cooperated less than the Americans. Similarly, another study found that people in China make less cooperative business decisions than Australians in the absence of a sanction system (X. P. Chen \& Li, 2005).

In sum, we think the data fits better with the theory that competition is not necessary for individualism (Oyserman et al., 2002). Individualism is often independent of competition. Individualism emphasizes striving to stand on one's own instead of out-doing others (Schneider et al., 2011). Furthermore, collectivism can underpin uncooperative behaviors. For example, people in China show vigilance towards their coworkers in competition (S. S. Liu et al., 2019). 
If the finding that collectivists compete more is a puzzle, one reasonable explanation might be that this increased competition only applies to outsiders. For example, later in this chapter we describe the finding that negotiators from collectivistic cultures are more likely to withhold information in their negotiations. Perhaps this is to be expected. Perhaps people in collectivistic cultures are withholding information because their negotiation counterparts are outsiders. They're opponents. In many negotiation practice cases, the two sides are opposing companies. If it's really about in-group versus out-group, people in collectivistic cultures should tone down their competitiveness with people inside their group.

Although this explanation sounds plausible, it does not fit the data. For example, other research has found that people in China withhold knowledge even from in-group members. In-depth interviews among employees have found competition and antagonism among Chinese co-workers, but not among Brazilian and Russian co-workers (Ardichvili et al., 2006). For example, Chinese interviewees expressed vigilance toward their coworkers: "If we are in the same line of work, we are enemies." Employees in China also tended to think of outcomes as zero-sum: "In China there are too many people for 'one cake' and so the competition is high." In addition, they expressed hesitance about sharing information: "Many people do not want to share the expertise they get through many years of hard working. The reason for this situation is competition."

But perhaps coworkers are not considered in-group members in China? Not so. In another study, participants in China rated colleagues and classmates as more of in-group members than participants in the United States (S. S. Liu et al., 2019). Yet despite calling coworkers in-group members, participants in China still expressed more suspicion toward them. Thus, a general in-group favoritism does not seem to explain the difference. Suspicion and competition pervade even within the group in collectivistic cultures.

\section{Is The Collectivism-Competition Link Just Corruption?}

In this chapter, we argue that intense competition is a part of collectivistic culture. Yet one alternative theory could be that this is an artifact of corruption or simple resource scarcity. If collectivistic cultures tend to be poorer, the competition might be a consequence of scarce resources. Similarly, living in a corrupt political system could create suspicion and vying behind the scenes.

These are plausible alternative explanations. They are plausible because it is true that collectivistic cultures are poorer on average (Hofstede, 2003; Talhelm, 2015). It is also true that collectivistic cultures have more corruption on average (Mazar \& Aggarwal, 2011). What's more, temporarily putting people in a more collectivistic mindset made them more willing to offer a bribe (Mazar \& Aggarwal, 2011). Thus, it's important to pull apart competition from poverty and corruption.

One way to tackle this question is to compare differences within the same country. Researchers did this by comparing northern and southern China (S. S. Liu et al., 2019). Although China is generally collectivistic, research has found evidence that rice-farming areas of southern China are more collectivistic than the wheat-farming north (Talhelm et al., 2014, 2018). In the south, paddy rice relied on irrigation networks that bound villages together to maintain and regulate water use. Paddy rice also required about twice as much labor as wheat, which pushed rice farmers to form cooperative labor exchanges (Talhelm \& Oishi, 2018). Thus, China offers a unique test case to compare regions that vary on collectivism within the same country. This helps rule out many of the variables that confound East-West comparisons, such as language, religion, and national political system.

Using the same competition scenarios from the study comparing the United States and China, researchers gave the scenarios to people from different parts of China (Talhelm \& Oishi, 2018). Although they were living under the same national political system, people from rice areas of China anticipated more unethical behaviors than people from wheat areas (Figure 26.2). Rice-wheat differences were just as strong after taking into account provincial measures of corruption and good governance (p. 5). 


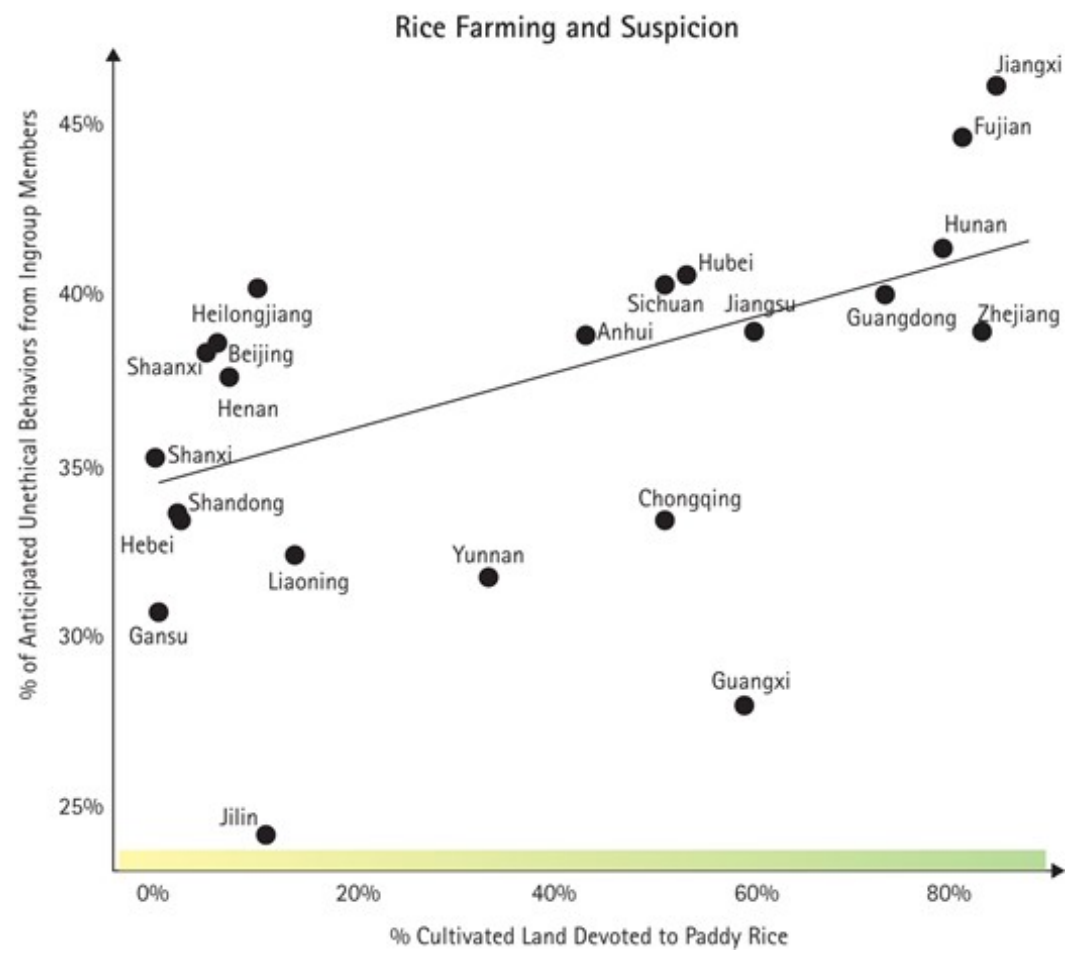

Rice farming predicts vigilance toward classmates and co-workers.

What about poverty and resource scarcity? It is true that collectivistic countries tend to be poorer. But within China, rice-farming provinces are actually wealthier on average (Talhelm et al., 2014). Thus, modern-day wealth could not explain the rice-wheat differences. In fact, provincial development (GDP per capita) did not significantly predict people's vigilance $(p=.640)$.

In sum, collectivism was a better explanation of the intense competition than corruption and resource scarcity. The idea that interdependence causes suspicion and intense competition apart from resource scarcity also fits with studies that have found differences between Hong Kong and the United States (Lam et al., 2004; L. M. W. Li et al., 2015). Hong Kong has a GDP per capita on par with the UK and other wealthy European countries. Yet the intense competition persists.

The case of rice farming suggests how it is possible to have both cooperation and intense competition in the same culture. For example, anthropologists observing traditional Japanese rice villages saw that farmers competed intensely with each other over water (Yoshida, 1984). This coexistence of cooperation and competition seems to be living on beyond the rice fields. In modern offices, employees in China saw their relationships with coworkers as both more cooperative and more competitive than Americans (Keller \& Loewenstein, 2011). In short, cooperation does not exclude competition. Interdependence only requires interdependence-not that that dependence be pleasant.

\section{Collectivistic Cultures Compete Covertly}

Humans around the world compete with each other. But how people compete depends on the social structure they live in. The how question can help resolve the paradox of why cultures that emphasize harmony still manage to harbor so much competition (Hsu, 1981). In collectivistic cultures, competition often gets channeled from direct, overt conflict into covert, tacit competition.

\section{Withholding Information}

One tacit competition strategy is withholding information. Withholding information is less direct and harder to detect than outright lying. Withholding also offers some amount of plausible deniability-a mechanism that saves face and minimizes conflict. 
participants were told this contact was trustworthy and had successfully worked with them in the past. In another condition, participants were told this contact was merely an acquaintance and had only met with them once or twice. Participants in China did not differ from Americans in sharing knowledge about the industry with a work partner they trust. However, participants in China withheld knowledge from an acquaintance more than Americans (Chow et al., 2000).

People from collectivistic cultures also withhold information during negotiations. In a series of studies, researchers had people from 10 cultures negotiate the same business deal (W. Adair et al., 2004; W. L. Adair \& Brett, 2005). While they were negotiating, researchers audiotaped their conversations and coded their behaviors. Negotiators from the traditionally individualistic cultures of the United States, Germany, Israel, and Sweden spent far more time communicating directly - sharing their priorities and giving feedback on their counterpart's offers.

In contrast, participants from traditionally collectivistic cultures Japan, Hong Kong, India, and Thailand shared far less information with their counterpart (Gunia et al., 2011). Rather than sharing information, they spent more time making offers back and forth. Withholding information may be a good strategy in simple negotiations, where two people haggle about a single price. But this negotiation had win-win tradeoffs that participants could find if they shared information about their true priorities. Because they had a harder time gathering this information, cultures that withheld information won fewer points on average.

This international study offers important data from countries that appear less often in the cultural psychology research on competition. Cross-cultural psychology research is not balanced across parts of the world. According to one calculation, there are six times as many studies about China, Korea, and Japan as there are about the three most-populous nations in Africa and South America (Talhelm \& Oishi, 2019). Much of the research we discuss in this chapter also comes from Mainland China and Hong Kong. That raises an important question: is the link between collectivism and competition unique to collectivism in China? Perhaps China is an aberration, and there are other "flavors" of collectivism more common around the world that really are harmonious.

One reason these negotiation studies are valuable is that they extend the sample to Thailand, India, and Japan, as well as other less-studied individualistic cultures. Russia also offers a useful datapoint. Negotiators in Russia withheld information similar to participants in other collectivistic cultures. Although Russia is a "middle culture" between East and West, studies have found that people in Russia score higher on collectivism and lower on individualism than people in Western Europe and North America (Gelfand et al., 2004; Grossmann \& Varnum, 2011; Hofstede, 2003; Suh et al., 1998). In sum, these studies suggest the link between collectivism and competition is not just a China phenomenon. It seems to extend to other lessstudied collectivistic cultures.

\section{Covert Competition Among Frenemies and In-group Vigilance}

In addition to withholding information as a form of covert competition, collectivists also harbor more vigilance towards people in their social group. Research in another less-frequently studied culture, Ghana, described competition among the in-group in a novel way (Adams, 2005). According to Adams, it is common in Ghana for people to be fearful of having an enemy among their friends or family-a "frenemy." Adams profiled cultural artifacts like bumper stickers that reflect a caution toward frenemies. For example, one local proverb warns, "if an insect bites you, it comes from inside your clothes" (p. 949).

Interviews backed up the cultural products. In Ghana, 71 percent of people reported being the target of an enemy versus 26 percent of Americans. Participants in America weren't just less likely to report having an enemy; they were doubtful of the idea itself. Many Americans were skeptical that frenemies really exist. As one American participant put it, if someone thought they had enemies among their friends, "I would think they were paranoid" (p. 953). In fact, 20 percent of Americans used the word "paranoid" to describe the fear of frenemies.

A study comparing students in Hong Kong and the United States found similar results (L. M. W. Li et al., 2015). Students in Hong Kong were more suspicious of their friends than Americans. For example, Hong Kongers were more likely to agree that "There are likely to be people in my close social network (relatives and friends) who feel hatred and ill will toward me." 
scholarship or for an acting role (S. S. Liu et al., 2019). Then they asked people to write what they thought the other students, actors, or work colleagues would do. Research assistants coded their responses as ethical (such as ethical "do research on the role"), unethical (such as "poison other actresses' food"), or gray area (such as "become buddy-buddy with the director"). In the U.S., 16 percent of imagined behaviors were unethical or gray area versus 38 percent in China. In short, people in collectivistic cultures report more suspicion and vigilance toward friends, colleagues, and even family.

\section{Why Would Collectivism Breed Competition and Suspicion?}

Why have some studies found that people in collectivistic cultures compete more? Here we discuss the beliefs that underpin competition. We entertain the explanation that differences in competition are based on people's basic beliefs about how the world is structured.

\section{Zero-Sum Beliefs}

Perhaps the most logical place to start is zero-sum beliefs. Zero-sum beliefs describe the idea that there is only a finite amount of resources, so one person's gains are another person's loss. If people in collectivistic cultures tend to believe that resources are finite, it would be rational to compete more as a result.

Researchers tested people's zero-sum beliefs in over 40 countries (Różycka-Tran et al., 2015, 2018). They found that people in collectivistic cultures and lower-income nations were more likely to endorse zero-sum beliefs. In these societies, people have to navigate tight social relationships and manage interpersonal obligations, all of which could exacerbate zero-sum beliefs. Recent research highlights the role of zero-sum beliefs as the culprit behind cultural differences in how vigilant people are towards in-group others. For example, people in more collectivistic regions in China believed more in the idea of zero sum, which in turn predicted greater in-group vigilance (S. S. Liu et al., 2019).

In perhaps the most convincing demonstration, researchers manipulated zero-sum beliefs and found that it changed people's expectations about competition (S. S. Liu et al., 2019). In the baseline condition, participants imagined working on an important project in the office, when a coworker comes by to offer help. Without any sort of priming, 21 percent of participants in China predicted that the coworker was secretly trying to sabotage them. In the US, just four percent predicted sabotage.

Next, researchers explicitly defined the company environment as zero-sum. In that condition, more people in the U.S. (25 percent) and China (35 percent) predicted sabotage. Then, when researchers explicitly defined the office as a win-win environment, predictions of sabotage fell (five to eight percent). It is interesting to note that the United States results were nearly identical when the situation was ambiguous and when the situation was explicitly win-win. These results suggest that (1) perceptions of the environment as zerosum cause people to be suspicious and (2) the baseline situation in China is similar to the explicitly zerosum condition.

\section{Social Comparison}

Another process that shapes competition is social comparison (Garcia et al., 2020). Baldwin \& Mussweiler (2018) found two cultural dimensions that explain variation in social comparison tendencies within the United States: tightness-looseness and individualism-collectivism. They used Google Correlate search data - a database of millions of search queries since 2003 in the United States - to obtain search frequencies of emotions related to social comparison, such as envy and resentment. They found that US states with more social comparison had tighter cultural norms and more relational self-construal. People in these states tended to Google more emotion words related to social comparison.

Cross-cultural comparisons also show that people in collectivistic cultures spend more time on social comparison (Chung \& Mallery, 1999; Sasaki et al., 2014). For example, researchers had European Canadian and Asian Canadian students complete a test. Afterwards, they gave them options to seek out as many of other students' rankings as they wished. They found that Asian Canadians sought out more social 
comparisons than Canadians of European descent, especially upward comparisons and comparisons after

failure. These tendencies were explained by higher self-reported collectivism (White \& Lehman, 2005).

There is also neural imaging research finding a link between culture and social comparison. One study measured people's sensitivity towards social comparison by having participants play a gambling game while researchers recorded activity in brain regions sensitive to reward (ventral striatum and the ventromedial prefrontal cortex; Kang et al., 2013). Americans showed greater neural activity in response to their absolute financial gain, whereas participants in Korea showed greater neural activity in response to financial gain relative to their partner in the game. This suggests that participants in Korea were more sensitive to social comparison, even without the potential confound of self-report surveys.

Research has found that giving participants social comparison information makes them more competitive in social games. However, this effect is particularly pronounced in Japan compared to the United States and Belgium (Toda et al., 1978). This is not surprising, given research showing that people's motivation to succeed in collectivistic cultures is often driven by social approval and upward comparison rather than internal standards (Niles, 1995; Sasaki et al., 2014). Qualitative accounts aptly illustrate the pressure to excel through social comparison. Asian American children report that their parents constantly compare their children to other people's children, berating their children for "only having a 4.0 GPA [when others] have a 4.3" (Becerra, 2008; Yang, 2011). In one qualitative interview study, an Asian American student described the "Asian scale" in relation to the immense pressure of social comparison at school: "A is for average; B is for bad; C is for crap; and F is find another a family" (Zhou \& Lee, 2017).

Asian and Asian Americans are also more likely to base their self-esteem on competition than White and Black Americans (Cheng \& Kwan, 2008; Crocker et al., 2003; C.-H. Liu et al., 2016). They agree more with scale items such as "my self-worth is affected by how well I do when I am competing with others" (Crocker et al., 2003). Because people from interdependent cultures base their self-worth more on outperforming other people, underperformance has worse consequences for them. For example, one study found that participants who were more interdependent reported lower self-esteem after witnessing a close friend's success (Sasaki et al., 2014).

In another study, European American and Asian American participants were asked to imagine themselves as a university student whose sister was either the valedictorian or on academic probation. The valedictorian situation represented upward social comparison, whereas the probation situation represented downward social comparison. Even though upward social comparison is potentially damaging, European Americans actually reported feeling better when they imagined their sister performing well. In contrast, Asian Americans reported feeling worse about themselves after upward social comparison and feeling better after downward social comparison (Sasaki et al., 2014).

Several studies have found that people from East Asia report lower subjective well-being than European Americans (Diener et al., 1995; Kitayama et al., 2000; Oishi et al., 1999). Comparing different nations, the East Asian "happiness gap" remains even when comparing happiness between East Asia and other countries that are just as wealthy (Diener et al., 1995). These contingencies of self-worth can partly explain cultural differences in well-being. People from East Asia are more likely to base their sense of self-worth on the approval of others, which is linked to an overall lower sense of well-being (C.-H. Liu et al., 2016). Similarly, social comparison can sometimes make people happy and sometimes make people unhappy. But research suggests that the costs are bigger than the benefits. The overall effect is that social comparison makes people unhappy (Fujita, 2008). This seems to be true across cultures-despite the fact that some social comparison is upward and some is downward, the overall effect is that social comparison is linked to less happiness in the United States and in China (Lee \& Talhelm, 2021).

\section{Common Standard versus Self-Defined Goals}

Another plausible cause of competition is whether people have a commonly defined or self-defined goals. People in interdependent cultures often define people's self-worth based on common standards and objective metrics such as grades, income, and awards. In cultures that define the self as independent, people have more latitude to define their worth based on their own standards.

In one study, we asked participants in United States and China to rate what characteristics (e.g., reading widely, having a logical mind) best describe an intelligent person (Wu \& Dunning, 2021a). Americans 
showed varying standards of what they think qualifies as intelligence, based on what characteristics of intelligence they have themselves. For instance, for American participants who read widely, their definition of intelligence tended to include the characteristic of reading widely. However, participants in China showed more of a common standard for what being intelligent entailed, regardless of what characteristics they have themselves.

In other words, people in the United States tend to have more fluid and idiosyncratic definitions of what they consider to be intelligent, creative, a good leader, and so on (Dunning et al., 1991; Dunning \& Cohen, 1992; Hayes \& Dunning, 1997). If people are not an avid reader but good at math, they simply adjust the standard of intelligence to being good at math. There would be little reason for them to compete with a person who is an avid reader. Yet, people in China share a common trait prototype. If being an avid reader is what is commonly acknowledged as intelligent (more so than being a math whiz), a person who is good at math would see herself as being less intelligent than a person who reads widely and have more incentive to compete.

Objective metrics of status also have more impact on well-being in East Asian cultures. In nationally representative surveys conducted in Japan and the United States, objective markers of status (e.g., education attainment) more strongly predicted psychological well-being such as life satisfaction and self-acceptance in Japan than in the United States. However, subjective markers of status (where people think they stand relative to others in their community) more strongly predicted psychological well-being in United States than in Japan (Curhan et al., 2014).

A recent study found similar differences comparing more collectivistic rice-farming regions of China to more individualistic wheat-farming regions (Lee \& Talhelm, 2021). In two large, nationally representative surveys, people's income and social status were stronger predictors of people's happiness in rice-farming areas than wheat-farming areas. Although wealthier people were happy all over China, income was more than twice as predictive in rice areas. This is consistent with the idea that people in interdependent cultures define happiness based on commonly shared markers-income and job status in this case. To the extent that people in a society are all striving for the same thing, social comparison and competition are more integral to success.

This tendency to strive for a common standard provides a path to understanding the "surprising" finding that people in collectivistic cultures tend to believe more that the world is zero-sum (Różycka-Tran et al., 2015). If people have more latitude to define their own self-worth, then one person's success does not have to reflect upon another person's success. When people have flexibility to define their self-worth, the son who makes a modest salary helping children as a public-school teacher has less impetus to begrudge his older brother who earns big money as a Wall Street consultant. Likewise, the American student with a middling SAT score but outstanding extracurriculars has far less reason to begrudge a classmate with a perfect SAT than a similar student in China. Because college admission in China hinges on a single test score, students have less wiggle room to resist being defined in a clear way to everyone.

\section{The Social Ecology of Competition: Relational Mobility}

So far, we have made a simple empirical claim: people in collectivistic cultures compete more intensely and endorse competition more than people in individualistic cultures. Yet it seems like a contradiction to say that we should find more competition in cultures that prioritize connectedness and relationships. Why would collectivism predict more competition?

One promising explanation to explain this seemingly paradoxical link is relational mobility. Relational mobility describes whether relationships in a society tend to be open, flexible, and easy to find (Thomson et al., 2018). A study of 39 countries found that countries in Western Europe and the Americas tend to be relationally mobile (Thomson et al., 2018). In contrast, countries in the Middle East and Asia tended to have fixed, stable relationships.

Interdependent cultures tend to be low in relational mobility, $r=.72$ (Thomson et al., 2018). Thus, low relational mobility describes most (but not all) interdependent cultures. Relational mobility helps set out the payoffs for different behaviors. If relationships tend to be fixed, and if it is hard to replace damaged relationships with new ones, it makes strategic sense to avoid open conflict. It also makes it more likely that two people who do not get along will have to still be around each other. 
In other words, relational mobility changes the payoffs for taking social risks in conflicts. When mobility is

low, it is riskier to damage relationships. Researchers tested this idea by asking people to rate how willing they would be to take social risks (L. M. W. Li et al., 2015). For example, how willing would you be to speak "your mind about an unpopular issue in a meeting at work?" Low relational mobility predicted less willingness to take social risks.

However, relational mobility did not mean people were simply risk-takers in general. They were no more likely to take ethical or financial risks, such as gambling a day's income. Instead, risk-taking was specific to the social world.

Results were similar when researchers experimentally manipulated people's perception of the social environment. When researchers asked participants to imagine being in a low-mobility social group, they saw social behaviors as riskier. In short, social environments with low relational mobility seem to make people more hesitant to take social risks.

At the same time, low relational mobility makes it harder for people to exit relationships after conflict arises. In social environments with lots of flexibility and choice, people have an easier time leaving people they have conflict with. For example, in the interviews about frenemies, 48 percent of Americans mentioned having choice in their relationships compared to just six percent of people in Ghana (Adams, 2005). One American interviewee couldn't understand "why one would continue to interact with somebody who one did not like" (p. 956). Yet in many collectivistic cultures, people do not see relationships as free to choose and dispose of.

The low mobility makes it so that people cannot easily get away from people they have grudges with. When people have more freedom of choice, they can simply separate from each other, like boxers going into their own corners. But low-mobility societies essentially force those boxers back together, round after round.

It would be naïve to think that collectivism makes conflict disappear. If some amount of conflict is inevitable, then that conflict paired with social risk aversion makes open conflict less likely. Studies suggest that people channel the conflict "underground" (S. S. Liu et al., 2021). Instead of competing directly, collectivists tend to compete covertly more often.

We bring together candidates for the causes of competition in collectivism in Figure 26.3. This model links foundational conditions (relational mobility and interdependence) to intermediate mechanisms (such as the difficulty of distancing oneself from rivals) to specific behaviors and outcomes (such as vigilance). While speculative, this model is rooted in the research we review here, and it provides testable hypotheses for future researchers to explore.

\section{Figure $\mathbf{2 6 . 3}$}

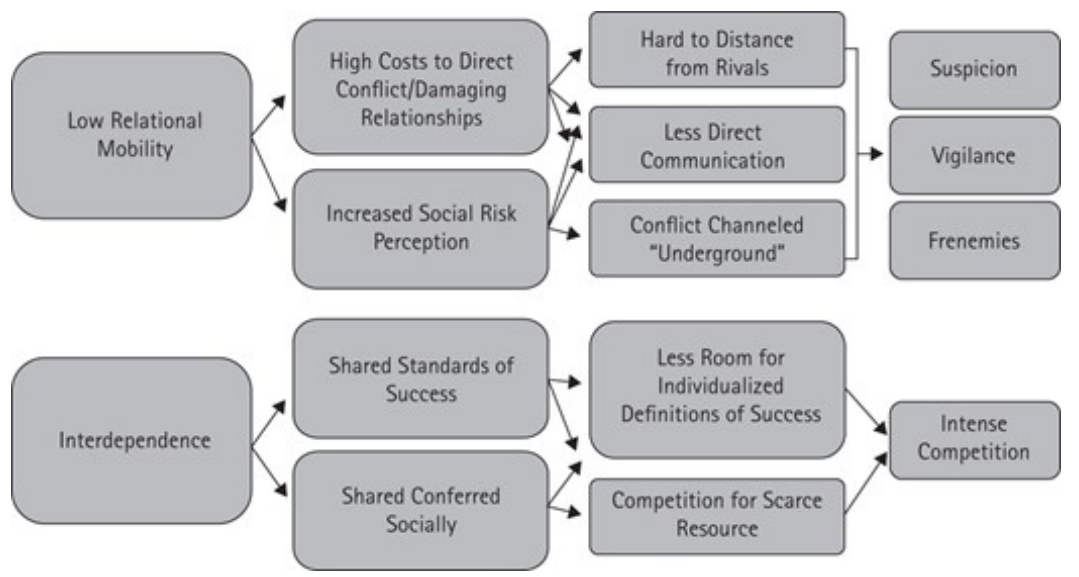

Theoretical model explaining causes of cultural differences in competition. 
Besides the question of how people compete after competition has started, there is also the question of how people enter conflict. Consider this: Would you rather be a stellar student in a mid-ranked university, or a below-average student in an Ivy League? We asked 273 students of East Asian and European American backgrounds if they preferred to be the metaphorical "big frog in a small pond" or the "small frog in a big pond" (Wu et al., 2018). Seventy-five percent of East Asian students chose to the "big pond"; only 59 percent of European American students chose so.

This competition entry preference translates to making decisions about which school to attend. We asked adults in the United States and China to choose between two college offers (Wu et al., 2018). They could accept an offer from a top-10 college, but their academic performance would be below average.

Alternatively, they could accept an offer from a top-100 college, where their academic performance would be above average. People in China were much more likely ( 58 percent) than European Americans (29 percent) to choose the top-10 college despite being below average on academic performance.

These differences are not just for school. Similar cultural differences appeared for work (Wu et al., 2018). More people in China said they would prefer working at one of the top-10 companies in the world, even though their performance would be below average. In contrast, more Americans said they would prefer to work at a top-100 company, where their performance would be above average (Figure 26.4).

\section{Figure 26.4}

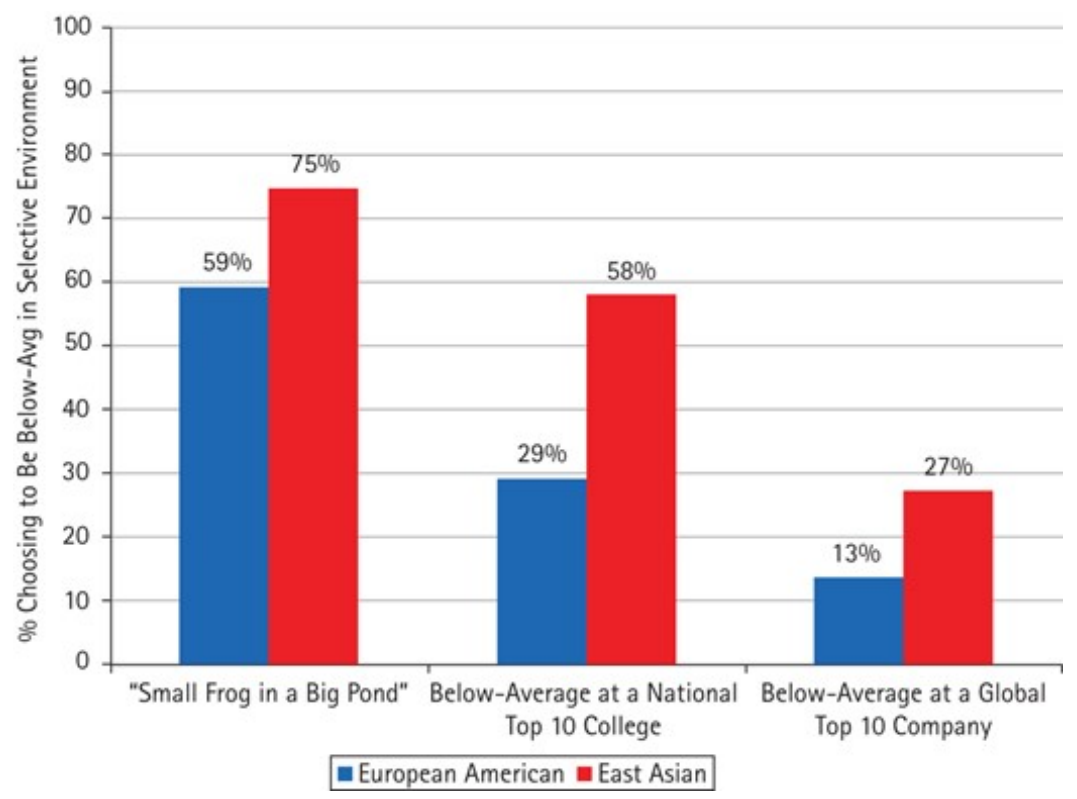

Percentage of European Americans versus East Asians choosing to be below-average in a selective environment rather than above-average in a less selective environment.

\section{Desire for Prestige}

Why would East Asians prefer the "big pond" more than European Americans? One possibility is that frogpond entry depends on self-construal. European Americans tend to focus on the self as independent from others, whereas East Asians tend to attune to a collective self embedded in social groups (Markus \& Kitayama, 2010). Given their emphasis on a collective self, East Asians may put more weight on intergroup comparisons ("I belong to a big pond") more than comparison within groups ("I am a big frog in this pond"). That emphasis on the group would logically cause people to prefer entering the "big pond" even at the expense of being a "small frog."

Yet when tested, people's tendencies to compare groups failed to explain cultural differences in entry decisions. Rather, the decision to vie for the "big pond" was driven by a greater desire for prestige (Wu et al., 2018). Why? East Asian countries are not just collectivistic. They share a face culture, wherein people gain face or respectability by attaining a position in the social hierarchy (Ho, 1976; Kim et al., 2010). The problem with face is that it is socially conferred, which means people cannot gain face by themselves. In a social hierarchy, people can only claim as much status as other people will grant them. 
In contrast, researchers have described mainstream American culture as a dignity culture (Kim \& Cohen, 2010; A. K.-Y. Leung \& Cohen, 2011). To have dignity is to hold the conviction that each individual is born with a level of inherent worth equal to everyone else. People's self-worth is intrinsic, inalienable, and independent of others' judgments and approval.

With this backdrop of face versus dignity, the "big pond" decision starts to make cultural sense. The "big pond" is prestigious, but it does not define people's sense of self-worth in dignity cultures. Going to a prestigious university does not guarantee success and going to a mid-tier university does not equal failure. However, things change in face cultures. If success and failure depend on what other people think, coming from a "big pond" sends a strong signal of one's social worth.

In line with this theory, an additional set of studies suggest that there is a social reward system in East Asian cultures that reinforces the "big pond" premium. East Asian employers place a premium on candidates coming from prestigious competition environments, even if their performance is subpar (Y. B. Li, 2018). Compared to Americans, people in China more strongly preferred to hire job applicants who had graduated from a top-10 college rather than a top-100 college, even when their academic performance was below average. In other words, it seems that employers' desires help motivate collectivists' choice to enter the "big pond."

\section{Consequence of Competition}

People from different cultures have varying perceptions about the consequences of competition. One study found that people in Hungary, for example, thought that competition may lead to sabotage and aggression (Watkins, 2006). In contrast, participants in the United States and Japan saw competition as contributing to individual improvement. But what are the actual consequences of competition?

\section{The Perils of Choosing a Competitive Environment}

Many students from East Asia go to great lengths to vie for elite schools. The past decade witnessed increasing frenzy of Chinese students attempting to get into elite universities in the West (Larmer, 2014). Along with it came "ghost" SAT testers and cheating scandals. Education consulting agencies proliferated in China, manufacturing application essays for students hungry for an elite Western education. Some agencies go so far as to groom children for an Ivy League education by sending them overseas at an age as early as nine (Qing et al., 2016).

Is entry into a prestigious competition environment worth it? This is a legitimate empirical question. Perhaps getting into elite schools is worth it because society will later reward the students for it. This is true in certain academic fields. One study looked at the United States academic job market in the disciplines of computer science, business, and history (Clauset et al., 2015). The prestige of a job candidate's doctoral program alone predicted job placement, such that the more prestigious the doctoral program, the more likely the student would get a job, and the more likely the job would be at a prestigious institution. In history, for example, top 10 universities produce three times the number of future faculty than universities ranked from 11 to 20.

However, do the benefits of prestigious schools carry over to job prospects outside of academia? Research suggests not. Dale and Krueger (Dale \& Krueger, 2014) tracked groups of college students for more than two decades. The students were from a variety of public and private universities and liberal arts colleges in the United States and went on to different career paths. The researchers found that all else equal, the prestige of a university or college had no impact on future earnings. For students with similar SAT scores, whether they attended a selective college made no difference on how much money they made in their careers.

Worse yet, studies point to psychological costs associated with attending elite schools. Correlational and longitudinal studies have found that high-performing students in less-selective schools ("big frog in a small pond") feel more competent, achieve higher grade point averages, and have greater career aspirations than low-performing students in more selective schools (Marsh et al., 2000, 2014). This is known as the "frog-pond effect," which suggests that being in the "big pond" as a "small frog" can harm students (Davis, 1966). It can make them feel lost and incapable, lagging behind their high achieving peers, even when they are doing well objectively. 
Alicke, Zell, and Bloom (2010) tested this idea out in an experiment. They divided each group of 10 people into two five-person groups. They had participants complete a lie-detection task and told them they ranked either fifth or sixth out of 10 people. For half of the participants, they told them an additional piece of information about their relative ranking: for people who ranked fifth, researchers told them they also ranked the worst in their five-person group ("small frog in a big pond"); for people who ranked sixth, they told them they also ranked the best in their five-person group ("big frog in a small pond").

Participants who were only told about their absolute ranking evaluated themselves similarly. Those ranked fifth did not think they performed significantly better on the lie detection test than those ranked sixth. However, when told about their relative ranking, people who ranked fifth and worst in their group evaluated their performance significantly worse than people who ranked sixth and best in their group. Being a small frog in a big pond makes people devalue themselves, even when they were performing better objectively.

So far, the evidence suggests that being in a prestigious environment comes with more costs than benefits. But most of these studies were conducted with Western samples. Do consequences of competing for the "big pond" carry over to non-Western cultures? Studies have replicated the "frog-pond effect" in 41 culturally and economically diverse countries across the globe (Marsh \& Hau, 2003; Seaton et al., 2009). Students across cultures evaluate themselves more negatively if they are under-performing in a selective school than if they are performing well in a less-selective school.

\section{Effects of Competition on Performance}

One large, open question in the field of culture and competition is the consequences. There is little research on the consequences of competition in non-Western cultures. We could find only one study that directly examined the effect of competition on performance and motivation outside the West. The researchers studied seventh graders in Hong Kong taking a course on Chinese typewriting (Lam et al., 2004). Researchers assigned the students to either a competition condition or a non-competition condition. In the competition condition, the students received a course certificate with their relative performance ranking printed on it. In the non-competition condition, the students just received a certificate. The study found that competition did boost performance. However, it only helped for easy tasks, not difficult tasks. Further, students evaluated themselves more negatively after failure.

At the end of the experiment, all students were told to complete one more test. They could choose an easy test which they would likely get a good score on or a difficult one which would help them learn more. More students in the competition condition chose the easy test on which they could perform well rather than the test that is better for learning.

This study speaks to the adverse consequence of competition in East Asian culture. However, research competition and performance across cultures is in its early stages. A meta-analysis of studies conducted with Western samples found no overall relationship between competition and performance (Murayama \& Elliot, 2012). The researchers found evidence of both competition prompting the motivation to do better than others and competition increasing the tendency to avoid doing worse than others. The former predicted better performance and the latter predicted worse performance. As the literature grows around the influence of culture on competition and performance, it is important to keep in mind that competition may be beneficial or detrimental to performance under different circumstances.

\section{Are There Collectivistic Societies Without Competition?}

We started this chapter by describing how researchers have connected collectivism to harmony and therefore low competition. The data collected since then has not only found that this idea was wrong. It was in the wrong direction. Collectivistic cultures tend to endorse competition and zero-sum beliefs more (S. S. Liu et al., 2019; Różycka-Tran et al., 2015). So where did that intuition come from? Are non-competitive collectivistic societies a figment of our imagination, or is it possible to have truly non-competitive collectivistic societies?

There are hints in anthropology research on traditional societies suggesting that they strongly oppose 
hunting to be competitive, yet this was not the case for the Chewong, a hunter-gatherer group living in the tropical rain forest of the Malay Peninsula (Howell, 1989). They also do not have words for "compete."

The ethnography suggests that competition may be a "hypocognized" concept in Chewong society. In other words, Chewong people may have few ideas about what competition entails and how competition can be interwoven into the fabric of their social relations and everyday activities (Howell, 1989; Levy, 1973). Without a societally established framework for a concept, people tend not to form associations around that concept (Levy, 1973; Wu \& Dunning, 2018a, 2018b). Nor can they readily recognize, identify, interpret, or remember instances and behaviors related to that concept (Wu \& Dunning, 2019, 2020, 2021b; Wu, 2021). For example, the Chewong people may have difficulty perceiving the activity hunting as associated with the concept "competition" because no conceptual schema of "competition" is engrained in their culture in the first place. Rather than saying the Chewong have no capacity for feeling competitive, it is probably more accurate to say that they reside in a culture where there is little need or motivation to develop principles and practices related to competition.

However, it would be a mistake to see traditional societies as uniformly collectivistic. In fact, inhabitants of what are termed "peaceful" societies focus strongly on individual autonomy (but not individual achievement or overshadowing others), egalitarianism, and voluntary relationships (Bonta, 1997). For example, the Buid people living on Mindoro Island in the Philippines place little value on kinship and dependence-hallmarks of many collectivistic cultures (Gibson, 1985). The Buid also minimize dyadic relationships, which they believe can lead to aggression and competition. Thus, some traditional societies may be peaceful, but not because they are collectivistic. Rather, they strongly embrace individualistic values to the extent that they eschew competition all together.

Instead of collectivism, ethnographies point to another dimension that separates societies that are highly competitive or not: flexibility of power hierarchy (Mead, 1937). If the status hierarchy is stable and consensually accepted, there is little competition. The military is a clear example of a clear power hierarchy that is relatively stable and where advancement is clearly defined. In that environment, competition is unlikely to change the status of an individual or a group.

But when status is changeable, competition becomes a means of attaining higher status. Animal research bears this out. Conflict increases and incurs more damage between similar-sized animals than animals with a large size or dominance discrepancy (Enquist \& Leimar, 1983; Reddon et al., 2019). When ambiguity exists in who holds the power, the likelihood of competition increases (Gould, 2003).

Note that the flexibility of power is a different dimension from the flexibility of finding friends and mates, as in relational mobility. Societies can have flexible interpersonal relationships but stable hierarchy. Across 37 societies, relational mobility is not significantly correlated with power distance $r(35)=-.27, p=.116$ (Thomson et al., 2018). For example, Mexico scores high on relational mobility and power distance.

Finally, we speculate that there is another condition that can create non-competitive collectivistic groups. In war and other competitions at the group level, individuals may unite to defeat other groups. For example, after the 9/11 terror attacks, opposing political parties in the United States voted together more frequently. Polls found Americans' pride in being American increased from 55 percent to 70 percent (Petrecca, 2017). Similarly, in his book Bowling Alone, sociologist Robert Putnam speculated that America's high social capital in the 1950 s and 1960 s stemmed from the unity of World War II (Putnam, 2000). Perhaps it is no accident that militaries seem to combine both elements-a common enemy and a well-defined hierarchy.

Research in sociology and economics has tested this "common enemy effect" - the idea that facing a common enemy increases group solidarity (De Jaegher \& Hoyer, 2012, 2016; McLauchlin \& Pearlman, 2012). Having to confront a common enemy, people from different social groups no longer think of things as "our group" versus "their group." Rather, they come to recategorize themselves as an inclusive "we" against their common enemy (Dovidio et al., 1993). Although the research on the common enemy effect does find that conflict with an enemy group can promote unity within the group, there are exceptions. External enemies fail to bring unity when there is already significant discord among group members. At times, common enemies can even strengthen disagreements and incite more conflict within the group (DeNardo, 1985; Olson, 1965). 
Across decades of studies, research has documented consistent differences in competition across cultures. One broad theme in those findings is that collectivistic cultures experience more intense competition than individualistic cultures. It is clear that the classic notion that collectivistic cultures emphasize "harmony" is only partly true. There is certainly evidence that people in collectivistic cultures avoid open conflict (Morris et al., 1998). However, people in collectivistic cultures tend to see the world as a competitive place, and they are more likely to suspect that people around them-even their friends-are competing with them beneath the surface.

We set out a model wherein these differences start not with abstract values, religious heritage, or language (Figure 26.3). Rather, we see these differences as stemming primarily from the social ecology. Environments with fixed relationships and few choices for meeting new people raise the costs of direct conflict. Similarly, strongly collectivistic societies share norms and definitions about what is valuable in life. When there is strong agreement about a narrow set of goals, it becomes harder for people to set their own goals and succeed in different, individual ways.

\section{Areas in Need of Future Research}

Much work is still undone. Few psychological studies have explored competition in Africa, Latin America, and the Middle East. Although we highlighted studies in collectivistic cultures outside East Asia, it is true that most of the studies on culture and competition have sampled collectivistic cultures in East Asia. It is important to understand whether the relationships between collectivism and competition here are general or unique to East Asia's type of collectivism.

A second area for future research is how competition could affect underrepresented groups. For example, competition is a part of college admissions, and getting into an elite college might influence people's earnings. Dale and Krueger (2014) found that university prestige did not matter for later income for students who had similar SAT scores. However, university prestige did make a difference for Black and Hispanic students, as well as first-generation students. A degree from an elite university predicted higher earnings later in life.

However, this elite status advantage only holds if the students finished their degrees in the first place. If students from underrepresented groups enter a "big pond" as the "small frog," they face the risk of feeling out of place in the competitive environment and failing to graduate altogether. One study found that Black and Hispanic students are less likely to complete STEM degrees at more prestigious universities (Elliott et al., 1996). These findings suggest that it is important that universities encourage students from underrepresented groups to pursue an elite college education; however, once they enter a selective environment, universities have to foster a welcoming enough environment to encourage them to stay (Phillips et al., 2020).

Another area ripe for research is cultural change. It is difficult to look in the cultural psychology research on competition and pull out any concrete guidance for how to change a culture of competition. For example, if a company or school finds that competition is undermining student achievement or mental health, what steps can cultural psychologists suggest to reduce competition or to channel it in a more productive direction? Similarly, if a company or sports team is finding performance and motivation lagging, what could they do to instill a more competitive culture? These areas are wide open for future research.

Finally, few psychology studies have looked at how the institutions that cultures create might reinforce competition. For example, perhaps people in China believe in the idea of competition in the first place and therefore create institutions based on competition. University admissions are certainly a human-created institution, and that institution is more explicitly based on competition (a single test score) in China than in the United States. This belief in competition and meritocracy goes back to the Tang Dynasty and the Imperial Exam system (Powers, 2020). If some cultures create systems that focus on competition, it could reinforce people's belief that competition is an inherent part of the world. 


\section{Competition Exists $\neq$ Liking Competition}

There is a phrase that appears frequently on Twitter: "retweet does not equal endorsement." Putting content on one's feed does not necessarily mean the person likes that content. Throughout the research we have covered here, even though we found that people in collectivistic cultures compete more, there is no evidence that they like competition. Nor did we find evidence that they think competition is good for people. Instead, the evidence simply says that competition is more common and more intense.

We think it is more likely that people in collectivistic cultures see competition simply as a part of how the world works. There are some hints of this if you look at specific questions about competition. For example, we analyzed questions given to 3,799 participants from the United States and Asia from the research website YourMorals.org. Participants from Asia agreed more with the item, "It is important to me that I do my job better than others" ( $d=0.36, p=.003$; Figure 26.5a). However, they did not agree more with the item saying they enjoy that competition: "I enjoy working in situations involving competition with others" $(d=$ $0.08, p=.392$; Figure 26.5b). A comparison of World Values Survey data across 56 countries found that people East Asia agreed the most with the statement "I hate to compete with people" (Minkov, 2018).

\section{Figure 26.5a}

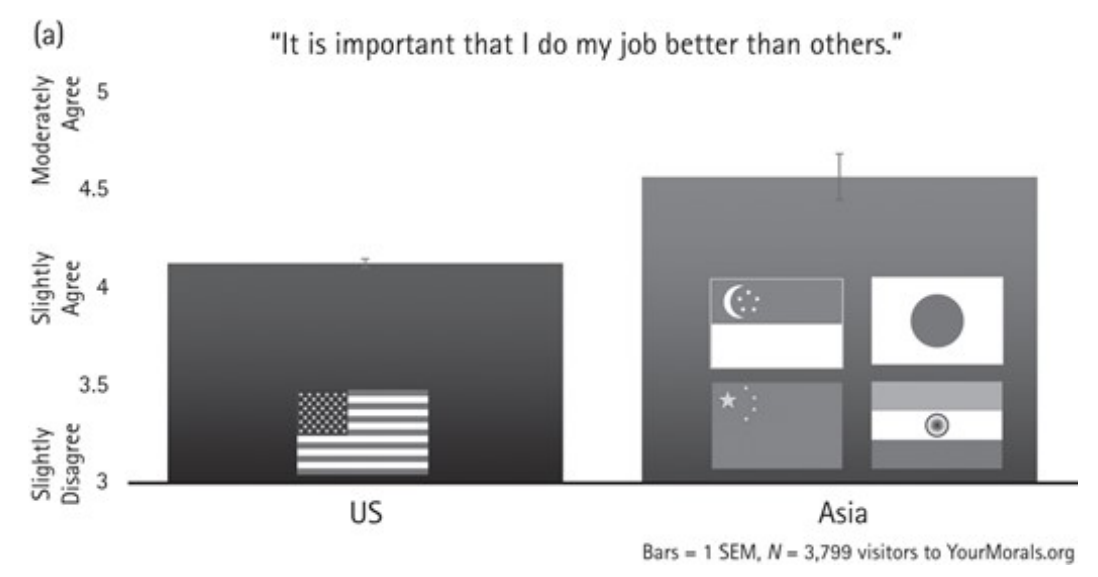

Agreement with the statement "It is important that I do my job better than others" in the United States versus Asia (China, Japan, Korea, India).

Figure 26.5b

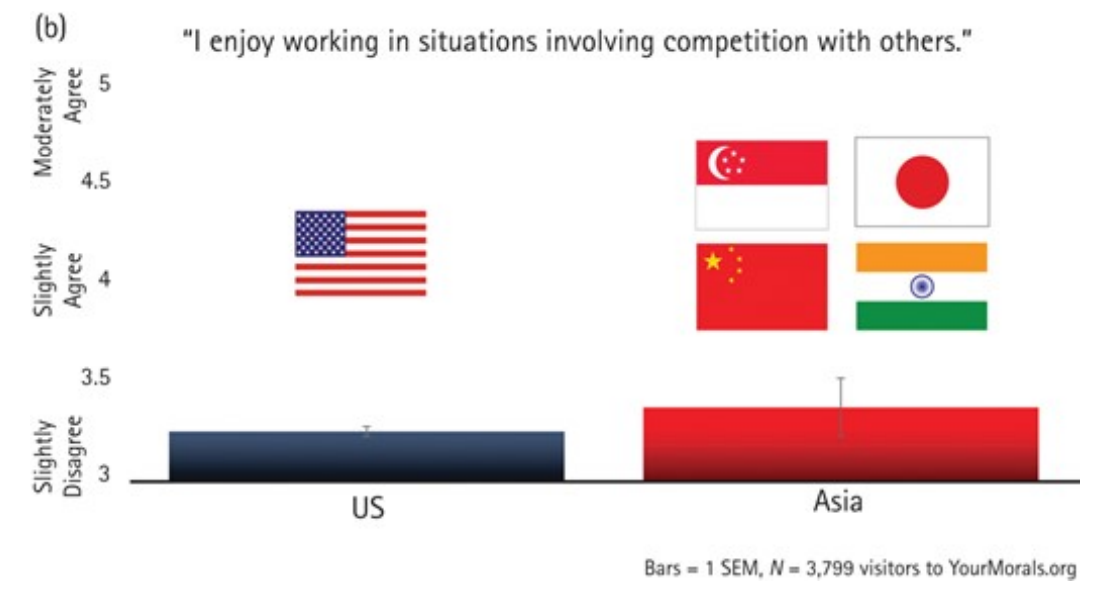

Agreement with the statement "I enjoy working in situations involving competition with others" in the United States versus Asia (China, Japan, Korea, India).

It is perhaps no wonder that some Chinese parents bemoan the fierce competition in Chinese education and choose to send their children overseas to study (Yan, 2015). One study conducted focus group interviews with Chinese parents about their view of Chinese education and Gaokao, a national college entrance exam similar to the SAT in the United States. Most Chinese parents viewed the entrance exam as overly competitive and unfair. They also expressed their wish for their children not to have to compete (Hu \& Hagedorn, 2014). 
Similarly, many people in Ghana reported believing in enemies, but this does not mean they liked being friends with enemies. Rather, people in Ghana simply said that to deny having enemies would be naïve. Similarly, people in East Asia seem to see competition as a part of life-prevalent yet unpleasant. Cultural differences do not always boil down to preferences. For collectivists, competition is simply a part of life. 
Adair, W., Brett, J., Lempereur, A., Okumura, T., Shikhirev, P., Tinsley, C., \& Lytle, A. (2004). Culture and negotiation strategy. Negotiation Journal, 20(1), 87-111. https://doi.org/10.1111/j.1571-9979.2004.00008.x.

Google Scholar WorldCat

Adair, W. L., \& Brett, J. M. (2005). The negotiation dance: Time, culture, and behavioral sequences in negotiation. Organization Science, 16(1), 33-51. https://doi.org/10.1287/orsc.1040.0102.

Google Scholar WorldCat

Adams, G. (2005). The cultural grounding of personal relationship: Enemyship in North American and West African worlds. Journal of Personality and Social Psychology, 88(6), 948-968. https://doi.org/10.1037/0022-3514.88.6.948.

Google Scholar WorldCat

Alicke, M. D., Zell, E., \& Bloom, D. L. (2010). Mere categorization and the Frog-Pond Effect. Psychological Science, 21(2), $174-177$. https://doi.org/10.1177/0956797609357718.

Google Scholar WorldCat

Ardichvili, A., Maurer, M., Li, W., Wentling, T., \& Stuedemann, R. (2006). Cultural influences on knowledge sharing through online communities of practice. Journal of Knowledge Management, 10(1), 94-107. https://doi.org/10.1108/13673270610650139.

Google Scholar WorldCat

Baldwin, M., \& Mussweiler, T. (2018). The culture of social comparison. Proceedings of the National Academy of Sciences of the United States of America 115(39), E9067-E9074. https://doi.org/10.1073/pnas.1721555115.

Google Scholar WorldCat

Becerra, H. (2008, July 16). Trying to bridge the grade divide. Los Angeles Times.

Bonta, B. D. (1997). Cooperation and competition in peaceful societies. Psychological Bulletin, 121(2), 299.

https://doi.org/10.1037/0033-2909.121.2.299.

Google Scholar WorldCat

Brewer, M. B., \& Chen, Y.-R. (2007). Where (who) are collectives in collectivism? Toward conceptual clarification of individualism and collectivism. Psychological Review, 114(1), 133-151. https://doi.org/10.1037/0033-295X.114.1.133.

Google Scholar WorldCat

Brewer, M. B., \& Gardner, W. (1996). Who is this "We"? Levels of collective identity and self representations. Journal of Personality and Social Psychology, 71(1), 83-93. https://doi.org/10.1037//0022-3514.71.1.83.

Google Scholar WorldCat

Chen, C. C., Chen, X., \& Meindl, J. R. (1998). How can cooperation be fostered? The cultural effects of individualism-collectivism. Academy of Management Review, 23(2), 285-304. https://doi.org/10.5465/amr.1998.533227.

Google Scholar WorldCat

Chen, X. P., \& Li, S. (2005). Cross-national differences in cooperative decision-making in mixed-motive business contexts: The mediating effect of vertical and horizontal individualism. Journal of International Business Studies, 36(6), 622-636.

https://doi.org/10.1057/palgrave.jibs.8400169.

Google Scholar WorldCat

Cheng, S. T., \& Kwan, K. W. K. (2008). Attachment dimensions and contingencies of self-worth: The moderating role of culture. Personality and Individual Differences, 45(6), 509-514. https://doi.org/10.1016/j.paid.2008.06.003.

Google Scholar WorldCat

Chow, C. W., Deng, F. J., \& Ho, J. L. (2000). The openness of knowledge sharing within organizations: A comparative study of the United States and the People's Republic of China. Journal of Management Accounting Research, 12(1), 65-95.

https://doi.org/10.2308/jmar.2000.12.1.65.

Google Scholar WorldCat

Chung, T., \& Mallery, P. (1999). Social comparison, individualism-collectivism, and self-esteem in China and the United States. Current Psychology, 18(4), 340-352. https://doi.org/10.1007/s12144-999-1008-0.

Google Scholar WorldCat 
Advances, 1(1), 1-6. https://doi.org/10.1126/sciadv.1400005.

Google Scholar WorldCat

Crocker, J., Luhtanen, R. K., Cooper, M. L., \& Bouvrette, A. (2003). Contingencies of self-worth in college students: Theory and measurement. Journal of Personality and Social Psychology, 85(5), 894-908. https://doi.org/10.1037/0022-3514.85.5.894.

Google Scholar WorldCat

Curhan, K. B., Levine, C. S., Markus, H. R., Kitayama, S., Park, J., Karasawa, M., Kawakami, N., Love, G. D., Coe, C. L., Miyamoto, Y., \& Ryff, C. D. (2014). Subjective and objective hierarchies and their relations to psychological well-being. Social Psychological and Personality Science, 5(8), 855-864. https://doi.org/10.1177/1948550614538461.

Google Scholar WorldCat

Dale, S. B., \& Krueger, A. B. (2014). Estimating the effects of college characteristics over the career using administrative earnings data. Journal of Human Resources, 49(2), 323-358. https://doi.org/10.3368/jhr.49.2.323.

Google Scholar WorldCat

Davis, J. A. (1966). The campus as a frog pond: An application of the theory of relative deprivation to career decisions of college men. American Journal of Sociology, 72(1), 17-31. https://doi.org/10.1086/224257.

Google Scholar WorldCat

De Jaegher, K., \& Hoyer, B. (2012). Cooperation and the common enemy effect. Discussion Paper Series nr: 12-24. Koopmans Research Institute, 12(24), 12-24.

Google Scholar WorldCat

De Jaegher, K., \& Hoyer, B. (2016). Collective action and the common enemy effect. Defence and Peace Economics, 27(5), 644664. https://doi.org/10.1080/10242694.2014.925676.

Google Scholar WorldCat

DeNardo, J. (1985). Power in numbers. Princeton University Press.

Google Scholar Google Preview WorldCat COPAC

Diener, E., Diener, M., \& Diener, C. (1995). Factors predicting the subjective well-being of nations. Journal of Personality and Social Psychology, 69(5), 851-864. https://doi.org/10.1037/0022-3514.69.5.851.

Google Scholar WorldCat

Domino, G. (1992). Cooperation and competition in Chinese and American children. Journal of Cross-Cultural Psychology, 23(4), 456-467. https://doi.org/10.1177/0022022192234003.

Google Scholar WorldCat

Dovidio, J. F., Gaertner, S. L., Anastasio, P. A., Bachman, B. A., \& Rust, M. C. (1993). The common ingroup identity model: Recategorization and the reduction of intergroup bias. European Review of Social Psychology, 4(1), 1-26.

https://doi.org/10.1080/14792779343000004.

Google Scholar WorldCat

Dunning, D., \& Cohen, G. L. (1992). Egocentric definitions of traits and abilities in social judgment. Journal of Personality and Social Psychology, 63(3), 341-355. https://doi.org/10.1037/0022-3514.63.3.341.

Google Scholar WorldCat

Dunning, D., Perie, M., \& Story, A. L. (1991). Self-serving prototypes of social categories. Journal of Personality and Social Psychology, 61(6), 957-968. https://doi.org/10.1037/0022-3514.61.6.957.

Google Scholar WorldCat

Elliott, R., Strenta, A. C., Adair, R., Matier, M., \& Scott, J. (1996). The role of ethnicity in choosing and leaving science in highly selective institutions. Research in Higher Education, 37(6), 681-709. https://doi.org/10.1007/BF01792952.

Google Scholar WorldCat

Enquist, M., \& Leimar, O. (1983). Evolution of fighting behaviour: Decision rules and assessment of relative strength. Journal of Theoretical Biology, 102(3), 387-410. https://doi.org/10.1016/0022-5193(83)90376-4.

Google Scholar WorldCat

Faris, N. (2018, October 26). Researcher at Queen's University, caught on video, admits to poisoning coworker. National Post.

Fujita, F. (2008). The frequency of social comparison and its relation to subjective well-being. In M. Eid \& R. J. Larsen (Eds.), The Science of subjective well-being (pp. 239-257). Guilford Press. 
Fülöp, M. (1999). Students' perception of the role of competition in their respective countries: Hungary, Japan, USA. In: A. Ross (Red.) Young citizens in Europe. University of North London, 195-219.

Google Scholar Google Preview WorldCat COPAC

Fülöp, M. (2000). Teachers' perception of the role of competition in their country: Hungary, Japan and the USA. Citizenship, Social and Economics Education, 4(3), 142-158. https://doi.org/10.2304/csee.2000.4.3.142.

Google Scholar WorldCat

Fülöp, M. (2005). The development of social, economical, political identity among adolescents in the post-socialist countries of Europe. Growing up in Europe Today: Developing Identities among Adolescents, January, 11-39.

WorldCat

Fülöp, M., Roland-Lévy, C., \& Berkics, M. (2004). Economic competition perceived by French and Hungarian adolescents. In Ross, A. (Eds.) The Experience of Citizenship (pp. 325-331). London: Metropolitan University.

Google Scholar Google Preview WorldCat COPAC

Fülöp, M., \& Sándor, M. (2006). Cross-cultural understandings from social psychology on cooperation and competition. In A. Ross (Ed.), Citizenship education: Europe and the world (pp. 75-88). CiCe.

Google Scholar Google Preview WorldCat COPAC

Furnham, A., Kirkcaldy, B. D., \& Lynn, R. (1994). National attitudes to competitiveness, money, and work among young people: First, second, and third world differences. Human Relations, 47(1), 119-132. https://doi.org/10.1177/001872679404700106. Google Scholar WorldCat

Garcia, S. M., Reese, Z. A., \& Tor, A. (2020). Social comparison before, during, and after the competition. In J. Suls, R. L. Collins, \& L. Wheeler (Eds.), Social comparison, judgment, and behavior (pp. 105-142). Oxford University Press.

https://doi.org/10.1093/oso/9780190629113.003.0005.

Google Scholar Google Preview WorldCat COPAC

Gelfand, M. J., Bhawuk, D. P., Nishii, L. H., \& Bechtold, D. J. (2004). Individualism and collectivism. In R. J. House, P. J. Hanges, M. Javidan, P. W. Dorfman, \& V. Gupta (Eds.), Culture, leadership and organizations: The GLOBE study of 62 societies (pp. 473-512). Sage.

Google Scholar Google Preview WorldCat COPAC

Gibson, T. (1985). The sharing of substance versus the sharing of activity among the Buid. Man, 20(3), 391.

https://doi.org/10.2307/2802438.

Google Scholar WorldCat

Gould, R. V. (2003). Collision of wills: How ambiguity about social rank breeds conflict. University of Chicago Press.

Google Scholar Google Preview WorldCat COPAC

Grimm, S. D., Church, A. T., Katigbak, M. S., \& Reyes, J. A. S. (1999). Self-described traits, values, and moods associated with individualism and collectivism: Testing I-C theory in an individualistic (U.S.) and a collectivistic (Philippine) culture. Journal of Cross-Cultural Psychology, 30(4), 466-500. https://doi.org/10.1177/0022022199030004005.

Google Scholar WorldCat

Grossmann, I., \& Varnum, M. E. W. (2011). Social class, culture, and cognition. Social Psychological and Personality Science, 2(1), 81-89. https://doi.org/10.1177/1948550610377119.

Google Scholar WorldCat

Gunia, B. C., Brett, J. M., Nandkeolyar, A. K., \& Kamdar, D. (2011). Paying a price: Culture, trust, and negotiation consequences. Journal of Applied Psychology, 96(4), 774-789. https://doi.org/10.1037/a0021986.

Google Scholar WorldCat

Hayes, A. F., \& Dunning, D. (1997). Construal processes and trait ambiguity: Implications for self-peer agreement in personality judgment. Journal of Personality and Social Psychology, 72(3), 664-677. https://doi.org/10.1037/0022-3514.72.3.664

Google Scholar WorldCat

Ho, D. Y. (1976). On the concept of face. American Journal of Sociology, 81(4), 867-884.

Google Scholar WorldCat

Hofstede, G. (2003). Culture's consequences: Comparing values, behaviors, institutions and organizations across nations. Sage. 
Houston, J. M., Harris, P. B., Moore, R., Brummett, R., \& Kametani, H. (2005). Competitiveness among Japanese, Chinese, and American undergraduate students. Psychological Reports, 97(1), 205-212. https://doi.org/10.2466/pr0.97.1.205-212.

Google Scholar WorldCat

Howell, S. (1989). "To be angry is not to be Human, but to be fearful is": Chewong concepts of human nature. In S. Howell \& R. Willis (Eds.), Societies at Peace: Anthropological Perspectives (pp. 45-59. Taylor \& Frances/Routledge.

Google Scholar Google Preview WorldCat COPAC

Hsu, F. L. K. (1981). Americans and Chinese: Passages to differences. University of Hawaii Press.

Google Scholar Google Preview WorldCat COPAC

Hu, J., \& Hagedorn, L. S. (2014). Chinese parents' hopes for their only children: A transition program case study. Journal of College Admission, 223, 34-42.

Google Scholar WorldCat

Kang, P., Lee, Y., Choi, I., \& Kim, H. (2013). Neural evidence for individual and cultural variability in the social comparison effect. Journal of Neuroscience, 33(41), 16200-16208. https://doi.org/10.1523/JNEUROSCI.5084-12.2013.

Google Scholar WorldCat

Keller, J., \& Loewenstein, J. (2011). The cultural category of cooperation: A cultural consensus model analysis for China and the United States. Organization Science, 22(2), 299-319. https://doi.org/10.1287/orsc.1100.0530.

Google Scholar WorldCat

Kim, Y.-H., \& Cohen, D. (2010). Information, perspective, and judgments about the self in face and dignity cultures. Personality and Social Psychology Bulletin, 36, 537-550. https://doi.org/10.1177/0146167210362398.

Google Scholar WorldCat

Kim, Y.-H., Cohen, D., \& Au, W.-T. (2010). The jury and abjury of my peers: The self in face and dignity cultures. Journal of Personality and Social Psychology, 98(6), 904-916. https://doi.org/10.1037/a0017936.

Google Scholar WorldCat

Kitayama, S., Markus, H. R., \& Kurokawa, M. (2000). Culture, emotion, and well-being: Good feelings in Japan and the United States. Cognition and Emotion, 14(1), 93-124. https://doi.org/10.1080/026999300379003.

Google Scholar WorldCat

Knight, G. P., Kagan, S., \& Buriel, R. (1981). Confounding effects of individualism in children's cooperation-Competition social motive measures. Motivation and Emotion, 5(2), 167-178. https://doi.org/10.1007/BF00993895.

Google Scholar WorldCat

Lam, S. F., Yim, P. S., Law, J. S. F., \& Cheung, R. W. Y. (2004). The effects of competition on achievement motivation in Chinese classrooms. British Journal of Educational Psychology, 74(2), 281-296. https://doi.org/10.1348/000709904773839888.

Google Scholar WorldCat

Larmer, B. (2014, December 31). Inside a Chinese test-prep factory. The New York Times.

Lee, C.-S., \& Talhelm, T. (2021). History of rice farming may explain lower happiness and more intense social comparison in East Asia than West. Manuscript under review.

Google Scholar Google Preview WorldCat COPAC

Leung, A. K.-Y., \& Cohen, D. (2011). Within- and between-culture variation: Individual differences and the cultural logics of honor, face, and dignity cultures. Journal of Personality and Social Psychology, 100(3), 507-526. https://doi.org/10.1037/a0022151. Google Scholar WorldCat

Leung, H., \& Au, W. T. (2010). Chinese cooperation and competition. In M. H. Bond (Ed.), The Oxford handbook of Chinese psychology (pp. 499-514). Oxford University Press. https://doi.org/10.1093/oxfordhb/9780199541850.013.0030.

Google Scholar Google Preview WorldCat COPAC

Levy, R. I. (1973). Tahitians: Mind and experience in the Society Islands. University of Chicago Press.

http://dx.doi.org/10.1016/j.cmet.2014.03.003.

Google Scholar Google Preview WorldCat COPAC 
cautious intimacy. Asian Journal of Social Psychology, 18 (2), 124-133. https://doi.org/10.1111/ajsp.12091.

Google Scholar WorldCat

Li, Y. B. (2018). Post-frog pond: Cultural variations in hiring decisions. University of Michigan.

Google Scholar Google Preview WorldCat COPAC

Liu, C.-H., Chiu, Y.-H. C., \& Chang, J.-H. (2016). Why do Easterners have lower well-being than Westerners? The role of others' approval contingencies of self-worth in the cross-cultural differences in subjective well-being. Journal of Cross-Cultural Psychology, 48 (2), 0022022116677580. https://doi.org/10.1177/0022022116677580.

Google Scholar WorldCat

Liu, S. S., Morris, M. W., Talhelm, T., \& Yang, Q. (2019). Ingroup vigilance in collectivistic cultures. Proceedings of the National Academy of Sciences of the United States of America, 116(29), 14538-14547. https://doi.org/10.1073/pnas.1817588116. Google Scholar WorldCat

Liu, S. S., Morris, M. W., Talhelm, T., \& Yang, Q. (2021). Covert competition in collectivistic cultures: The role of relational mobility. Manuscript under review.

Google Scholar Google Preview WorldCat COPAC

Markus, H. R., \& Kitayama, S. (1991). Culture and the self: Implications for cognition, emotion, and motivation. Psychological Review, 98(2), 224-253. https://doi.org/10.1037/0033-295X.98.2.224.

Google Scholar WorldCat

Markus, H. R., \& Kitayama, S. (2010). Cultures and Selves: A cycle of mutual constitution. Perspectives on Psychological Science, 5(4), 420-430. https://doi.org/10.1177/1745691610375557.

Google Scholar WorldCat

Marsh, H. W., \& Hau, K.-T. (2003). Big-fish-little-pond effect on academic self-concept: A cross-cultural (26-country) test of the negative effects of academically selective schools. American Psychologist, 58(5), 364-376. https://doi.org/10.1037/0003066X.58.5.364.

Google Scholar WorldCat

Marsh, H. W., Kong, C.-K., \& Hau, K.-T. (2000). Longitudinal multilevel models of the big-fish-little-pond effect on academic selfconcept: Counterbalancing contrast and reflected-glory effects in Hong Kong schools. Journal of Personality and Social Psychology, 78(2), 337-349. https://doi.org/10.1037/0022-3514.78.2.337.

Google Scholar WorldCat

Marsh, H. W., Kuyper, H., Morin, A. J. S., Parker, P. D., \& Seaton, M. (2014). Big-fish-little-pond social comparison and local dominance effects: Integrating new statistical models, methodology, design, theory and substantive implications. Learning and Instruction, 33, 50-66. https://doi.org/10.1016/j.learninstruc.2014.04.002.

Google Scholar WorldCat

Mazar, N., \& Aggarwal, P. (2011). Greasing the palm: Can collectivism promote bribery? Psychological Science, 22(7), 843-848. https://doi.org/10.1177/0956797611412389.

Google Scholar WorldCat

McLauchlin, T., \& Pearlman, W. (2012). Out-group conflict, in-group unity? Exploring the effect of repression on intramovement cooperation. Journal of Conflict Resolution, 56(1), 41-66. https://doi.org/10.1177/0022002711429707.

Google Scholar WorldCat

Mead, M. (1937). Cooperation and competition among primitive peoples. McGraw-Hill.

Google Scholar Google Preview WorldCat COPAC

Minkov, M. (2018). A revision of Hofstede's model of national culture: Old evidence and new data from 56 countries. Cross Cultural and Strategic Management, 25(2), 231-256. https://doi.org/10.1108/CCSM-03-2017-0033.

Google Scholar WorldCat

Morris, M. W., Williams, K. Y., Leung, K., Larrick, R., Mendoza, M. T., Bhatnagar, D., Li, J., Kondo, M., Luo, J., \& Hu, J. (1998). Conflict management style: Accounting for cross-national differences. Journal of International Business Studies, 29(4), 729-747. https://doi.org/10.1057/palgrave.jibs.8490050.

Google Scholar WorldCat

Murayama, K., \& Elliot, A. J. (2012). The competition-performance relation: A meta-analytic review and test of the opposing processes model of competition and performance. Psychological Bulletin, 138(6), 1035-1070. https://doi.org/10.1037/a0028324. 
Niles, F. S. (1995). Cultural differences in learning motivation and learning strategies: A comparison of overseas and Australian students at an Australian university. International Journal of Intercultural Relations 19(3), 369-385. https://doi.org/10.1016/01471767(94)00025-S.

Google Scholar WorldCat

OECD. (2018). Student co-operation and competition. In PISA 2018 results: What school life means for students' lives: Vol. III (pp. 119-128). OECD Publishing. https://doi.org/10.1787/19963777.

Google Scholar Google Preview WorldCat COPAC

Oishi, S., Diener, E., Suh, E., \& Lucas, R. E. (1999). Value as a moderator in subjective well-being. Journal of Personality, 67(1), 157-184. https://doi.org/10.1111/1467-6494.00051.

Google Scholar WorldCat

Olson, M. (1965). The logic of collective action. Harvard University.

Google Scholar Google Preview WorldCat COPAC

Overing, J. (1986). Images of cannibalism, death and domination in a "non-violent" society. Journal de La Société Des Américanistes, 72(1), 133-156. https://doi.org/10.3406/jsa.1986.1001.

Google Scholar WorldCat

Oyserman, D., Coon, H. M., \& Kemmelmeier, M. (2002). Rethinking individualism and collectivism: Evaluation of theoretical assumptions and meta-analyses. Psychological Bulletin, 128(1), 3-72. https://doi.org/10.1037/0033-2909.128.1.3. Google Scholar WorldCat

Pan, L. (2013, April). What can we learn from China's college murders? The Atlantic.

Petrecca, L. (2017, September 11). America's division: We united in the wake of 9/11, then partisanship re-emerged. USA Today.

Phillips, L. T., Stephens, N. M., Townsend, S. S. M., \& Goudeau, S. (2020). Access is not enough: Cultural mismatch persists to limit first-generation students' opportunities for achievement throughout college. Journal of Personality and Social Psychology, 119(5), 1112-1131. https://doi.org/10.1037/pspi0000234.

Google Scholar WorldCat

Powers, M. (2020). China and England: The preindustrial struggle for justice in word and image. Routledge.

Google Scholar Google Preview WorldCat COPAC

Putnam, R. D. (2000). Bowling alone: The collapse and revival of American community. Simon and Schuster.

Google Scholar Google Preview WorldCat COPAC

Qing, K. G., Harney, A., Stecklow, S., \& Pomfret, J. (2016, May 25). How an industry helps Chinese cheat their way into and through US colleges. Reuters.

Reddon, A. R., Dey, C. J., \& Balshine, S. (2019). Submissive behaviour is mediated by sex, social status, relative body size and shelter availability in a social fish. Animal Behaviour, 155, 131-139. https://doi.org/10.1016/j.anbehav.2019.06.026.

Google Scholar WorldCat

Roberts, K., Clark, S. C., Fagan, C., Adibekian, A., Tholen, J., Nemiria, G., \& Tarkhnishvili, L. (2000). Surviving post-communism: Young people in the former Soviet. Edward Elgar Publishing.

Google Scholar Google Preview WorldCat COPAC

Różycka-Tran, J., Alessandri, G., Jurek, P., \& Olech, M. (2018). A test of construct isomorphism of the belief in a zero-Sum game scale: A multilevel 43-nation study. PLoS ONE, 13(9), 1-15. https://doi.org/10.1371/journal.pone.0203196.

Google Scholar WorldCat

Różycka-Tran, J., Boski, P., \& Wojciszke, B. (2015). Belief in a zero-sum game as a social axiom: A 37-nation study. Journal of Cross-Cultural Psychology, 46(4), 525-548. https://doi.org/10.1177/0022022115572226.

Google Scholar WorldCat

Sasaki, J. Y., Ko, D., \& Kim, H. S. (2014). Culture and self-worth: Implications for social comparison processes and coping with threats to self-worth. In F. Gibbons \& Z. Križan (Eds.), Communal functions of social comparison (pp. 231-251). Cambridge University Press.

Google Scholar Google Preview WorldCat COPAC 
Schneider, B. H., Benenson, J., \& Berkics, M. (2011). Cooperation and competition. In P. K. Smith \& C. H. Hart (Eds.), The WileyBlackwell handbook of childhood social development (2nd ed., pp. 472-490). Blackwell Publishing Ltd.

Google Scholar Google Preview WorldCat COPAC

Seaton, M., Marsh, H. W., \& Craven, R. G. (2009). Earning its place as a pan-human theory: Universality of the big-fish-little-pond effect across 41 culturally and economically diverse countries. Journal of Educational Psychology, 101(2), 403-419.

https://doi.org/10.1037/a0013838.

Google Scholar WorldCat

Singelis, T. M., Triandis, H. C., Bhawuk, D. P. S., \& Gelfand, M. J. (1995). Horizontal and vertical dimensions of individualism and collectivism: A theoretical and measurement refinement. Cross-Cultural Research, 29(3), 240-275.

https://doi.org/10.1177/106939719502900302.

Google Scholar WorldCat

Sparkes, K. K. (1991). Cooperative and competitive behavior in dyadic game-playing: A comparison of Anglo-American and Chinese children. Early Child Development and Care, 68(1), 37-47. https://doi.org/10.1080/0300443910680105.

Google Scholar WorldCat

Suh, E., Diener, E., Oishi, S., \& Triandis, H. C. (1998). The shifting basis of life satisfaction judgments across cultures: Emotions versus norms. Journal of Personality and Social Psychology, 74(2), 482-493. https://doi.org/10.1037/0022-3514.74.2.482. Google Scholar WorldCat

Swenson, K. (2018, December 21). He suspected his roommate left the racist graffiti. He didn't know about the poison. The Washington Post.

Talhelm, T. (2015). The rice theory of culture. University of Virginia.

Google Scholar Google Preview WorldCat COPAC

Talhelm, T., \& Oishi, S. (2018). How rice farming shaped culture in Southern China. In A. K. Uskul \& S. Oishi (Eds.), Socioeconomic environment and human psychology (pp. 53-76). New York, NY: Oxford University Press.

Google Scholar Google Preview WorldCat COPAC

Talhelm, T., \& Oishi, S. (2019). Culture and ecology. In D. Cohen \& S. Kitayama (Eds.), Handbook of cultural psychology (pp. 119143). The Guilford Press.

Google Scholar Google Preview WorldCat COPAC

Talhelm, T., Zhang, X., \& Oishi, S. (2018). Moving chairs in Starbucks: Observational studies find rice-wheat cultural differences in daily life in China. Science Advances, 4(4), 1-10. https://doi.org/10.1126/sciadv.aap8469.

Google Scholar WorldCat

Talhelm, T., Zhang, X., Oishi, S., Shimin, C., Duan, D., Lan, X., \& Kitayama, S. (2014). Large-scale psychological differences within China explained by rice versus wheat agriculture. Science, 344(6184), 603-608. https://doi.org/10.1126/science.1246850.

Google Scholar WorldCat

Tang, S. (1999). Cooperation or competition: A comparison of U.S. and Chinese college students. Journal of Psychology: Interdisciplinary and Applied, 133(4), 413-423. https://doi.org/10.1080/00223989909599752.

Google Scholar WorldCat

Taylor, P. (2013). The thirty-six stratagems: A modern interpretation of a strategy classic. Infinite Ideas.

Google Scholar Google Preview WorldCat COPAC

Thomson, R., Yuki, M., Talhelm, T., Schug, J., Kito, M., Ayanian, A. H., Becker, J. C., Becker, M., Chiu, C., Choi, H.-S., Ferreira, C. M., Fülöp, M., Gul, P., Houghton-Illera, A. M., Joasoo, M., Jong, J., Kavanagh, C. M., Khutkyy, D., Manzi, C., ... Visserman, M. L. (2018). Relational mobility predicts social behaviors in 39 countries and is tied to historical farming and threat. Proceedings of the National Academy of Sciences, 115(29), 7521-7526. https://doi.org/10.1073/pnas.1713191115.

Google Scholar WorldCat

Toda, M., Shinotsuka, H., McClintock, C. G., \& Stech, F. J. (1978). Development of competitive behavior as a function of culture, age, and social comparison. Journal of Personality and Social Psychology, 36(8), 825-839. https://doi.org/10.1037/0022-

3514.36.8.825.

Google Scholar WorldCat

Triandis, H. C., Bontempo, R., Villareal, M. J., Asai, M., \& Lucca, N. (1988). Individualism and collectivism: Cross-cultural perspectives on self-ingroup relationships. Journal of Personality and Social Psychology, 54(2), 323-338. 
https://doi.org/10.1037/0022-3514.54.2.323.

Google Scholar WorldCat

Triandis, H. C., \& Gelfand, M. J. (1998). Converging measurement of horizontal and vertical individualism and collectivism. Journal of Personality and Social Psychology, 74(1), 118-128. https://doi.org/10.1037/0022-3514.74.1.118.

Google Scholar WorldCat

Vignoles, V. L., Owe, E., Becker, M., Smith, P. B., Easterbrook, M. J., Brown, R., González, R., Didier, N., Carrasco, D., Cadena, M. P., Lay, S., Schwartz, S. J., Des Rosiers, S. E., Villamar, J. A., Gavreliuc, A., Zinkeng, M., Kreuzbauer, R., Baguma, P., Martin, M., ... Bond, M. H. (2016). Beyond the "East-West" dichotomy: Global variation in cultural models of selfhood. Journal of Experimental Psychology: General, 145(8), 966-1000. https://doi.org/10.1037/xge0000175.

Google Scholar WorldCat

Watkins, D. A. (2006). The role of competition in today's Hong Kong: The views of Hong Kong Chinese adolescents in comparative perspective. Journal of Social Sciences, 2(3), 85-88. https://doi.org/10.3844/jssp.2006.85.88.

Google Scholar WorldCat

Watkins, D. A. (2010). Motivation and competition in Hong Kong secondary schools: The students' perspective. In C. K. K. Chan \& N. Rao (Eds.), Revisiting the Chinese learner (pp. 71-88). Springer. https://doi.org/10.1007/978-90-481-3840-1 Google Scholar Google Preview WorldCat COPAC

White, K., \& Lehman, D. R. (2005). Culture and social comparison seeking: The role of self-motives. Personality \& Social Psychology Bulletin, 31(2), 232-242. https://doi.org/10.1177/0146167204271326.

Google Scholar WorldCat

Wu, K. (2021). Invisibility of social privilege to those who have it. Academy of Management Proceedings 2021 (1).

https://doi.org/10.5465/AMBPP.2021.27

Google Scholar WorldCat

Wu, K., \& Dunning, D. (2018a). Unknown unknowns: The problem of hypocognition. Scientific American Mind, 29(6), 42-45.

https://doi.org/10.1038/scientificamericanmind1118-42.

Google Scholar WorldCat

Wu, K., \& Dunning, D. (2018b). Hypocognition: Making sense of the landscape beyond one's conceptual reach. Review of General Psychology, 22(1), 25-35. https://doi.org/10.1037/gpr0000126.

Google Scholar WorldCat

Wu, K., \& Dunning, D. (2019). Hypocognitive mind: How lack of conceptual knowledge confines what people see and remember. https://doi.org/10.31234/osf.io/29ryz.

Google Scholar Google Preview WorldCat COPAC

Wu, K., \& Dunning, D. (2020). Hypocognition and the invisibility of social privilege. In S. R. Thye \& E. J. Lawler (Eds.), Advances in group processes (Vol. 37, pp. 1-23). Emerald Publishing Limited. https://doi.org/10.1108/S0882-614520200000037001.

Google Scholar Google Preview WorldCat COPAC

Wu, K., \& Dunning, D. (2021a). Culture and self-view: Variation in trait conceptions. Manuscript in preparation.

Google Scholar Google Preview WorldCat COPAC

Wu, K., \& Dunning, D. (2021b). Invisibility of social privilege to those who have it. https://doi.org/10.31234/osf.io/tuy8m.

Google Scholar Google Preview WorldCat COPAC

Wu, K., Garcia, S. M., \& Kopelman, S. (2018). Frogs, ponds, and culture: Variations in entry decisions. Social Psychological and Personality Science, 9(1), 99-106. https://doi.org/10.1177/1948550617706731.

Google Scholar WorldCat

Yamagishi, T. (1988). The provision of a sanctioning system in the United States and Japan. Social Psychology Quarterly, 51(3), 265. https://doi.org/10.2307/2786924.

Google Scholar WorldCat

Yamagishi, T. (2003). Cross-societal experimentation on trust: A comparison of the United States and Japan. In E. Ostrom \& J. Walker (Eds.), Trust and reciprocity: Interdisciplinary lessons from experimental research (pp. 352-370). Russell Sage Foundation.

Google Scholar Google Preview WorldCat COPAC 
Yamagishi, T., Hashimoto, H., \& Schug, J. (2008). Preferences versus strategies as explanations for culture-specific behavior. Psychological Science, 19(6), 579-584. https://doi.org/10.1111/j.1467-9280.2008.02126.x.

Google Scholar WorldCat

Yan, A. (2015, March 25). Why Chinese parents are sending their children abroad to study at a younger age. South China Morning Post.

Yang, W. (2011). Paper Tigers. New York Magazine.

Yoshida, T. (1984). Spirit possession and village conflict. In E. Krauss, T. Rohlen, \& P. Steinhoff (Eds.), Conflict in Japan (pp. 85104). University of Hawaii Press.

Google Scholar Google Preview WorldCat COPAC

Zhou, M., \& Lee, J. (2017). Hyper-selectivity and the remaking of culture: Understanding the Asian American achievement paradox. Asian American Journal of Psychology, 8(1), 7-15. https://doi.org/10.1037/aap0000069.

Google Scholar WorldCat

Zhuang, P. (2013, April 21). Poisoning, death of Fudan student recalls disturbing case of Zhu Ling. South China Morning Post.

\section{Note}

1 We use the terms "collectivism" and "individualism" throughout this paper. However, cultural psychologists have used other similar terms, such as "interdependence" and "independence." Although some researchers have made distinctions between the different terms (Brewer \& Chen, 2007; Brewer \& Gardner, 1996), researchers generally use the terms interchangeably (Oyserman et al., 2002). 